\title{
RÁDIO UEPA: O PROJETO DE CRIAÇÃO DE RÁDIO EM SALA DE AULA PARA TURMAS DE EFL
}

\author{
Erika Silva $^{1}$ \\ Wellington Oliveira²
}

RESUMO: O presente artigo tem por objetivo relatar a experiência do projeto Rádio UEPA, aplicado em uma turma de graduação em Licenciatura em Letras Língua Inglesa da Universidade do Estado do Pará (UEPA), orientado pela professora da disciplina de Recursos Tecnológicos para o Ensino de Inglês. O projeto foi parte de avaliação da turma e teve por intuito relacionar os aspectos da escrita colaborativa com aspectos da fala para o ensino de Inglês como Língua Estrangeira. Desta forma, aperfeiçoando o desempenho de futuros professores de Inglês para a sala de aula, e trabalhando diferentes tecnologias, as quais podem futuramente servir como ferramentas de trabalho.

PALAVRAS-CHAVE: Rádio. Escrita colaborativa. Fala. Tecnologias.

\section{Introdução}

Este artigo tem como objetivo relatar a experiência vivida na aplicação do projeto Rádio UEPA, realizado em uma turma de vinte e oito alunos do segundo ano do curso de Letras - Língua Inglesa, da Universidade do Estado do Pará (UEPA), sob a orientação da professora mestre da disciplina Recursos tecnológicos para o ensino de inglês, que tem por objetivo apresentar as tecnologias disponíveis para utilização nos ambientes de ensino e aprendizagem de língua inglesa. A professora, no mesmo ano, também, ministrava a disciplina Inglês II, que além dos aspectos das habilidades de leitura e escrita, trata de assuntos referentes à organização textual e de algumas modalidades distintas.

Apresentaremos algumas teorias que sustentaram nosso projeto e os trabalhos que utilizamos como base para construção, como, por exemplo, o texto de Garcia (2006) que trata dos passos para se realizar um programa de rádio. Pontuaremos, também, alguns processos utilizados na construção do projeto, como a escrita colaborativa, a escrita como processo, a abrangência dos gêneros oferecida pelo gênero de programa de rádio, aspectos pragmáticos da fala - em

\footnotetext{
1 Universidade do Estado do Pará (UEPA) - Mestre em Análise da Interação (UFPA). Tem interesse nas áreas de Linguística Aplicada, Recursos Tecnológicos no ensino de língua estrangeira, Estudos Pragmáticos e Formação de Professores. Atualmente atua no Curso de Letras - Língua Inglesa da Universidade do Estado do Pará (UEPA). E-mail: erika.sue81@gmail.com

2 Universidade do Estado do Pará (UEPA) Graduando em Letras - Língua Inglesa pela Universidade do Estado do Pará. E-mail: wellington_ruan07@hotmail.com
} 
que utilizamos Burns e Goh (2012) -, e como se deu a constituição da experiência.

Este tipo de abordagem se faz relevante uma vez que a nossa sociedade atual

\begin{abstract}
Vivencia uma realidade em que as crianças nascem e crescem manuseando as tecnologias que estão ao seu alcance. [...] A era da informação é fruto do avanço das novas tecnologias que estocam, de forma prática, o conhecimento e gigantescos volumes de informações. [...] Estas novas tecnologias permitem-nos acessar não apenas conhecimentos transmitidos por palavras, mas também por imagens, sons, vídeos, dentre outros (VIANA, 2004, p. 11-12).
\end{abstract}

Seja através dos smartphones, ou dos computadores habituais, a tecnologia se faz presente cada vez mais na vida cotidiana. As fronteiras escolares não se restringem mais aos livros didáticos e aos quadros negros. Frente a esse novo contexto, um contexto de mudanças, Mercado (2002) argumenta que o professor necessita saber orientar corretamente seus alunos sobre onde buscar novas informações, ajudando no manuseio e na utilização da mesma. Dessa forma, se faz necessário a introdução desses aspectos na graduação de formação de professores, pois, através da utilização da tecnologia de forma prática, ainda no contexto de formação, o futuro profissional tem a oportunidade de refletir sobre qual a melhor maneira de se levar a tecnologia até a sala de aula, em outras palavras, os futuros professores devem receber uma formação que os deixem aptos a interagir com uma geração mais atualizada e informada.

Por fim, apesar da rádio não ser uma tecnologia recente, a escolha de incorporar os programas de rádio em práticas escolares, levando em consideração as várias possibilidades que essa atividade - cotidiana de grande parte dos alunos - nos oferece, se fez pertinente, possibilitando a construção do discurso na língua-alvo, além da exposição à quantidade de gêneros textuais que constituem os programas de rádio. 


\section{Processo: dos primeiros contatos aos últimos detalhes}

O projeto consistiu na integração de gêneros escritos e orais do programa de rádio e foi construído gradativamente, dividido em várias etapas, desde a seleção de textos que abordassem a construção de um script de rádio até a gravação final da parte oral. O primeiro passo fora a leitura de um artigo sobre a construção de um programa de rádio, Como fazer um programa de rádio, de Garcia (2006), em que obtivemos a noção concreta do que seria necessário para a construção do roteiro. Lemos também o artigo Escrita colaborativa em inglês como língua adicional: produção online e presencial em contexto universitário ${ }^{3}$, o qual nos deu um correto direcionamento sobre como construir o roteiro juntos, utilizando ferramentas para a escrita colaborativa como o Google Docs e a escrita em sala de aula a partir da orientação.

A temática foi decidida pelo grupo. Dessa forma, decidiu-se, então, pela construção de um programa de rádio informativo, mas ao mesmo tempo voltado para o entretenimento. Em um primeiro momento cada integrante do grupo escreveu a parte que lhe coube, uma vez que o programa foi dividido em notícias musicais, criticas cinematográficas, séries de TV, entrevistas com celebridades etc. Após isso, os textos foram organizados em ordem e modificados de acordo com o tempo do programa e do grau de importância e inovação das informações.

No decorrer do processo, os textos eram modificados e corrigidos levando em consideração as orientações dadas pela professora e a correção gramatical da língua inglesa feita em conjunto. Ao fim do processo de criação do roteiro, começamos com os ensaios para a gravação final. Durante os ensaios, foram corrigidas questões de postura, pronúncia e entonação, assim como os detalhes finais do roteiro.

Nos primeiros ensaios, por exemplo, os integrantes se mostraram um pouco tímidos à exposição, porém no decorrer do processo, houve um engajamento de todos e a ajuda coletiva quanto a questões de pronúncia. A partir disso, foram escolhidos os sons de background (BG) que fariam parte de nossa

\footnotetext{
3 LEANDRO, Diêgo Cesar; WEISSHEIMER, Janaína; COOPER, Jennifer Sarah. Escrita colaborativa em Inglês como Língua Adicional: produção online e presencial em contexto universitário. Hipertextus Revista Digital, v. 10, p. 1-18, 2013.
} 
gravação, cada integrante selecionava o som de BG que estivesse mais de acordo com o seu assunto tratado -, por exemplo, quem falou de filmes Jurassic World e Finding Dory, pesquisou pelas trilhas sonoras que compõem tais filmes e alguns efeitos sonoros que também fariam parte para dar certa fluência ao discurso.

A gravação final ocorreu em dois dias para que houvesse tempo suficiente para todas as correções que ainda fossem necessárias. Ao todo foram cinco grupos que gravaram seus programas. Ao fim, os áudios foram editados pela orientadora, que adicionou as trilhas e efeitos sonoros, e postados no site soundcloud e na página do projeto no facebook.

\section{Escrita colaborativa}

Este foi sem dúvidas um dos principais desafios, uma vez que o texto deveria ser escrito com outras oito pessoas e não de modo individual. Esse era 0 grande desafio, contudo a montagem do roteiro por partes fora facilitadora para 0 processo. No primeiro momento, antes mesmo de lermos os textos de apoio e guias, conversamos sobre a temática e que papel cada integrante deveria exercer dentro do projeto, tentamos integrar todos, já que todos deveriam participar dos processos de escrita do roteiro e gravação do programa maneira igual.

Após a decisão da temática que regeria nossos textos, cada integrante escreveu uma parte sua do roteiro, o que foi logo entregue para orientação. Em seguida, um documento de edição online foi aberto no Google Docs a fim de que os integrantes pudessem digitar seus textos para a montagem do roteiro integral, "as plataformas wiki, incluindo-se o Google Docs, têm potencial para promover a interatividade e a colaboração" (WEISSHEIMER et al., 2007, p. 05).

Para nós, alunos do curso de licenciatura em língua inglesa, o projeto serviu também para que conhecêssemos algumas ferramentas novas que nos serão de fundamental importância, pois, futuramente, nós seremos os professores e como diz Weissheimer (Id, p. 04), 
formal, o que inclui o domínio de línguas adicionais. [...] Os cursos de licenciatura devem, assim, inserir a questão tecnológica no currículo, a fim de preparar profissionais melhores, capazes de se manter no mercado.

$\mathrm{Na}$ grade curricular do curso de Licenciatura plena em Letras - Língua inglesa, temos a disciplina de recursos tecnológicos, a disciplina que nos levou a organizar este projeto de rádio, a fim de levar a inserção de futuros professores ao mundo tecnológico, apresentando-os ferramentas consistentes para o ensino e aprendizagem de L2.

A edição em grupo do roteiro nos possibilitou a correção não só de nossas partes, mas também a dos colegas de grupo, de forma que pudemos dar sugestões e compartilhar informações. Adaptamos nosso texto após a leitura do artigo de Garcia sobre o programa de rádio, no qual ele explica a necessidade de um script, "Este orienta que entonação a voz deverá ter para passar a ideia de tensão e distensão. O script é um guia seguro que possibilita ao radialista saber o que irá dizer e como irá fazê-lo" (GARCIA, 2006). Além da necessidade, Garcia nos dar um modelo de roteiro, que fora seguido para a produção do nosso.

O objetivo do nosso programa era informar. Criamos um programa informativo, cultural e popular, como uma mesa redonda sobre os temas atuais, onde haveria compartilhamento de informações acerca de filmes, músicas e séries de TV. Garcia (2006) diz que o gênero popular assemelhasse bastante com o gênero variedade, acreditamos que no nosso programa desenvolvido, tivemos a integração dos três gêneros: variedade, informativo e popular. A escrita teve que ser feita com bastante atenção, levando em consideração os atos de fala e o nível de formalidade e descontração exigida pelos gêneros em questão. Burns e Goh (2012, p. 79) afirmam que os textos escritos podem ser uma espécie de guia speech-like (fale como).

A adaptação final do roteiro foi feita durante os primeiros ensaios, em que houve a sinalização da posição correta dos BGs e dos efeitos sonoros, assim como as entonações corretas do que seria dito. A ordem de fala dos participantes, também fora diversas vezes alterada, tanto para dar coerência ao texto, quanto para dar fluência ao mesmo. Com o script montado, passamos à fase de ensaios e gravações, na qual começamos a trabalhar com a parte oral da língua. 


\section{Speaking: conclusão do projeto por meio da gravação final}

A última fase do projeto fora a gravação final, em que a professora providenciou os recursos necessários para a gravação do áudio. Contudo, até o dia da gravação, passamos por vários momentos de ensaios contínuos, apresentando o que estávamos desenvolvendo, a fim de tomarmos as orientações necessárias para que o processo de fala não se tornasse algo mecanizado ou artificial e sim natural - o uso de estratégias linguísticas como as hesitações, pausas breves e assim por diante (GOH; BURNS, 2012, p. 79) -, levando em consideração o gênero de rádio, pois, como dizem ainda Burns e Goh (Id.), há uma grande variação nos contextos e condições onde a linguagem é produzida.

Houve também os ensaios em grupos que eram feitos antes dos momentos de orientação. Nestes, era possível identificar a ajuda mutua novamente. Dessa forma, a colaboração não se limitou somente à escrita, mas, também, à fala - em seus mais diferentes aspectos - e à postura. Burns e Goh (2012, p. 79), acrescentam que os falantes, no desenvolvimento do speaking, necessitam do feedback dos outros interlocutores, já que interações de modo pessoal no que diz respeito à fala e o retorno dos ouvintes são partes importantes para que não haja nenhuma perda no entendimento. Assim, o foco girou entorno do sucesso do grupo como um todo e não de modo individual.

O gênero de programa de rádio é importante para a imersão da língua alvo em contextos sociais, como aconteceu no projeto: cada grupo trabalhou um gênero textual diferente, como entrevistas, exposições, comerciais etc., dessa forma, causando uma diversidade no projeto de rádio. $O$ uso real da língua é muito importante para estudantes de English as a Foreign Language (EFL), pois, como pontuado por Burns e Goh (2012, p. 75-76), a maioria dos materiais didáticos preparados para esses estudantes traz diálogos que muitas vezes não condizem com os aspectos da língua falada em sua naturalidade, ou seja, apresentam diálogos lentos e pausados e com vocábulos simples, ou seja, diálogos sintéticos. Contudo, esses diálogos não são totalmente inúteis, uma vez 
que podem ser aplicados aos estudantes iniciantes de EFL, almejando-se um fácil entendimento inicial e não além.

Visto que nós como estudantes de EFL - futuros professores - e nossos possíveis futuros alunos estarão em nossas atuais posições, não temos muitas oportunidades de praticar o idioma na vida diária - o que seria fundamental, uma vez que "seres humanos desenvolvem primeiramente as habilidades de fala para posteriormente aprenderem a se comunicar através da escrita, e a fala predomina durante o dia a dia" (GOH; BURNS, 2012, p. 78) - , como fora diversas vezes levantado em discussões na sala de aula durante as orientações para a importância de uma entonação e pronúncia apropriada, com vocábulos acessíveis para que se houvesse um entendimento pleno das proposições comunicativas. Silva e Souza (2014, p. 181 apud BEDJOU, 2006) pontuam "a autenticidade das emissões radiofônicas em aulas de ensino de inglês como língua estrangeira, autenticidade esta que realmente contribui para uma prática mais próxima dos contextos reais de comunicação [...]" para demonstrar isso, a professora apresentou à classe alguns programas de rádio facilmente encontrados em plataformas online na internet. A partir disso, começamos a realização de nosso projeto.

O projeto nos serve também como uma futura atividade, levando em consideração nossa formação, a ser executada, pois como acentuam Burns e Goh (2012, p. 75-79), os estudantes de EFL precisam utilizar a língua em contextos mais complexos fora da sala de aula, então, se torna importante ao professor estar preparado para atrair a atenção de seus alunos para os aspectos da língua falada, os dando oportunidades de praticar o uso da língua em diferentes contextos. Assim, não só trabalharemos como aspectos falados, mas também escritos. Hyland (2003, p. 01), afirma que, como professores de EFL, nossos principais objetivos envolvem conceituação e planejamento - visto que no gênero de programa de rádio, um integra o outro.

\footnotetext{
4 Tradução nossa.
} 


\section{Rádio UEPA: construção e ação}

Como dito anteriormente, dividiu-se a sala em oito grupos e cada grupo ficou responsável pela idealização e constituição de um programa de rádio. $O$ grupo do qual participei escolheu por título Talk Squad (Esquadrão da fala), que tinha como objetivo informar e entreter o público ouvinte. O programa teve uma subdivisão em assuntos específicos, tais como: música, filmes e séries; cada um sendo discutido por um ou dois integrantes. Tinha-se também o apresentador, que mediava os assuntos entre ouvintes e convidados e tinha por responsabilidade, também, os avisos e comentários. Da mesma forma, também tínhamos um convidado especial (ouvinte), que participava do programa através da plataforma Skype.

Quando se iniciou o programa, o apresentador fez uma breve introdução dos participantes e sobre os assuntos a serem tratados. O primeiro tópico, envolvendo música, tratou de uma conversa sobre a turnê 1989 da cantora Taylor Swift e uma enquete sobre o tema. Após, ainda no tema musical, tratou-se de shows a serem executados no Brasil, como a turnê Honeymoon, pontuando-se que a data do show coincidira com a data do Exame Nacional do Ensino Médio ENEM.

Logo após, tivemos o intervalo comercial - o que fora de responsabilidade de outro grupo - que falava sobre atrações musicais em Belém na época do Círio, mês de Outubro. Levou-se também em consideração, para a escolha do comercial, a correlação com o programa, assim, obtendo-se a coerência entre os mesmos. Seguindo o comercial, houve a exposição de filmes de aventura, como Jurassic World; e filmes de animação da Disney/Pixar, como Cars 3, The Incredibles 2, Toy Story 4 e Finding Dory.

Correlacionado aos filmes, outra participante iniciou o assunto de séries, expondo seu parecer sobre as futuras temporadas de alguns seriados, como The Walking Dead e Once Upon A Time, seguindo com o gênero crítica. E por fim, o último assunto foi sobre dublagem de algumas séries. Um dos participantes era profissional no assunto, tendo assim propriedades para falar do mesmo, fazendo um relato de experiência como dublador da série Sense8. No final do programa, o 
apresentador fez algumas perguntas ao convidado especial e este concorreu a dois prêmios, encerrando, assim, o programa e agradecendo aos participantes.

\section{Considerações finais}

O projeto foi de fundamental importância, pois durante o processo houve a imersão em diversas teorias de uso de tecnologia em sala de aula e reflexões de ensino, o que nos enriqueceu, de certa forma, de conhecimentos para uso posterior, tendo em vista que nossa formação concerne em futuros profissionais para o ensino de idiomas.

Pudemos entender, através do projeto, também, como a organização é necessária para a realização dos processos a fim de se atingir determinado objetivo. Já que o projeto gerou a cooperação entre as partes para que tudo fosse realizado da melhor forma possível, ou seja, gerou uma aprendizagem colaborativa e organizada. Percebemos que essa abordagem de interação entre os alunos é fundamental para a participação igualitária de todos e para que se gere e compartilhe uma diversidade criativa nas atividades.

Por fim, é relevante pontuar também que o papel do professor como um orientador sempre presente e disposto é de suma importância. Durante o desenvolvimento do nosso projeto, a professora nos fora um dos principais esteios, oferecendo materiais, dando dicas e orientações, e pedindo tudo nos prazos previstos, utilizando como base o projeto-piloto que acontecera no ano anterior.

\section{RADIO UEPA: THE RADIO CRIATION PROJECT IN THE CLASSROOM TO EFL STUDENTS}

\footnotetext{
ABSTRACT: This article reports the experience we had with the project Radio UEPA, applied in a undergraduate class in the English Language Degree of the Universidade do Estado do Pará (UEPA), guided by the professor of the discipline of Technological Resources for the English Language Teaching. The project was part of the evaluation of the class and aimed to relate the aspects of collaborative writing with aspects of speech for teaching English as a Foreign Language. Desta forma, aperfeiçoando o desempenho de futuros professores de Inglês para a sala de aula, e trabalhando diferentes tecnologias, as quais podem futuramente servir como ferramentas de trabalho.
} 
KEYWORDS: Radio. Collaborative Writing. Speaking. Technologies.

\section{Referências}

GARCIA, R. Como fazer um programa de rádio. In: GARCIA, R. Webrádio: Técnicas de produção, montagem e edição. Apostila, 2006. Disponível em: <http://audiocidades.utopia.com.br/manuais/manuais_programa_radio.html>. Acesso em: 20 out. 2015.

GOH, C. M. C; BURNS, A. Speech features, grammar and pronunciation. In: Teaching speaking: a holistic approach. Cambridge, 2012.

HYLAND, K. Second language writing. Cambridge, 2003.

LEANDRO, D.C.; WEISSHEIMER, J.; COOPER, J.S. Escrita colaborativa em inglês como língua adicional: produção online e presencial em contexto universitário. Revista hipertextus, v.10, Julho. 2013. Disponível em: $<$ http://www.hipertextus.net/volume10/04-Hipertextus-Vol10-Diego-CesarLendro_Janaina-Weissheimer\&Jennifer-Sarah-Cooper.pdf>. Acesso em: 18 nov. 2015.

MERCADO, L. P. L. Formação docente e novas tecnologias. In: Novas tecnologias na educação: reflexões sobre a prática. EDUFAL, Maceió, 2002.

SILVA, E. S. C.; SOUZA, A. L. A. Criação de programas de rádio em aulas de EFL. Contexturas, São Paulo, № 24, p. 171-190, 2015.

VIANA, M. A. P. Internet na Educação: Novas formas de aprender, necessidades e competências no fazer pedagógico. In: MERCADO, L. P. L. (Org.) Tendências na utilização das tecnologias da informação e comunicação na educação. Maceió: EDUFAL, 2004.

WEISSHEIMER, J; BERGSLEITHNER, J; LEANDRO, D. C. Escrita colaborativa com Google docs na aprendizagem de inglês como língua adicional. In: BECK, M. S.; SILVEIRA, R.; FUNCK, S. B.; XAVIER, R. P. (Organizadoras). Anais do III Congresso Internacional da ABRAPUI. Universidade Federal de Santa Catarina. Florianópolis. ISBN: 978-85-98703-12-1. 